\title{
Coexistence of Suprasellar Lesion and Pulmonary Congestion: Two Rare Cases and Literature Review
}

\author{
Jun Xiong ${ }^{1}$, Huijun Wang ${ }^{2}$, Yin Bao ${ }^{2}$ and Yongxing Sun ${ }^{1 *}$ \\ ${ }^{1}$ Department of Anesthesiology, Sanbo Brain Hospital, Capital Medical University, Beijing, China \\ ${ }^{2}$ Department of Anesthesiology, Beijing Tongren Hospital, Capital Medical Univertisty, Beijing, China
}

*Corresponding author: Yongxing Sun, Department of Anesthesiology, Sanbo Brain Hospital, Capital Medical University, No. 50, Yikesong, Xiangshan, Haidian District, Beijing, 100093, China

\begin{tabular}{|c|c|}
\hline ARTICLE INFO & ABSTRACT \\
\hline $\begin{array}{l}\text { Received: 慧 April 06, } 2020 \\
\text { Published: 慧 April 20, } 2020\end{array}$ & $\begin{array}{l}\text { Background: The characteristics of sellar/suprasellar lesion are endocrine } \\
\text { disturbance, obesity and sleepiness disorder. However coexistence suprasellar lesion } \\
\text { with pulmonary congestion is extremely rarely reported. }\end{array}$ \\
\hline $\begin{array}{l}\text { itation: Jun Xiong, Huijun Wang, Yin Bao, } \\
\text { ongxing Sun. Coexistence of Suprasellar } \\
\text { esion and Pulmonary Congestion: Two } \\
\text { are Cases and Literature Review. Bi- } \\
\text { med J Sci \& Tech Res 27(1)-2020. BJSTR. }\end{array}$ & $\begin{array}{l}\text { Case presentation: Two cases in the present report included typical traits of sellar/ } \\
\text { suprasellar tumor, besides they were identified preoperative pulmonary congestion } \\
\text { by chest computer tomography. Abnormal hormone level accompanying with obesity } \\
\text { induced and accelerated preoperative pulmonary congestion. Because coexistence of } \\
\text { sellar/suprasellar lesion with pulmonary congestion is very rare, we confirmed the } \\
\text { ultra-rare cases by literature reviewing. }\end{array}$ \\
\hline $\begin{array}{l}\text { Keywords: Suprasellar; Pulmonary Con- } \\
\text { gestion; Obesity; Erdheim-Chester Disease; } \\
\text { Obstructive Sleep Apnea; Endocrine }\end{array}$ & $\begin{array}{l}\text { Conclusion: Implementation of general anesthesia to patients with sellar/ } \\
\text { suprasellar lesion is a challenge to every anesthesiologist due to their complex } \\
\text { pathophysiological changes. Occurrence of pulmonary congestion increases extra } \\
\text { burden to anesthesiologists. Because ignorance of the accompanying pulmonary } \\
\text { congestion might produce irretrievable disaster, the importance of preoperative } \\
\text { evaluation and makeup of anesthesia plan should be stressed. Additional, the diagnosis } \\
\text { of the second case was Erdheim-Chester disease, a very rare disease in children. This } \\
\text { was the forth youngest case of this disease reported by searching PubMed and PMC. }\end{array}$ \\
\hline
\end{tabular}

\section{Introduction}

The overwhelmingly lesion in sellar/suprasellar region is pituitary adenomas, however this region can be affected by a variety of non-pituitary lesions, including craniopharyngiomas, cystic nonneoplastic lesions, inflammatory lesions, and so on $[1,2]$. Given that various diseases occurring in this region, as well as high operative risks, therefore arriving at the right preoperative diagnosis is important for taking appropriate therapeutic decisions, for instance, selecting surgical approach and necessity, ameliorating surgical complications [3]. Implementation of anesthesia to patients suffering sellar/suprasellar lesions is a challenge to every anesthesiologist, due to these lesions frequently accompanying with various neurologic and endocrine dysfunction, depending on properties of lesion, and mass effect on adjacent structures [4]. For instance, space-occupying mass may squeeze pituitary stalk, such compression is able to lead to development of endocrine disorders [5]. Meanwhile, sellar/suprasellar tumor might lead to obesity by different pathophysiologic mechanisms and produce various clinical symptoms [6]. The development of obesity deteriorates patient quality of life, but also raises airwaymanagement problem to anesthesiologists. Here we reported two cases of superasellar lesion, which had to undergo stereotactic biopsy for preoperative diagnosis. Except common symptoms, such as hormone deficiency, sleep disorder and obesity, both of them appeared obvious preoperative pulmonary congestion. The coexistence of superasellar lesion and pulmonary congestion is very rare. Detailed PubMed and PMC search for sellar/suprasellar lesion associated with pulmonary congestion yielded very few case, we demonstrated its rarity by literature review. Different anesthesia implemented to the two cases produced different clinical results. Awareness is needed of new pathological entities in sellar/suprasellar lesions. We discussed the potential causes for coexistence of sellar/suprasellar lesion and pulmonary, which was useful to better and comprehensive preoperative evaluation. 


\section{Case report}

\section{Case 1}

A 5-year-old girl (Table 1) was admitted to our hospital presenting polydipsia and polyuria. Her symptoms were presented three years ago. Except that, she had no relevant medical history. Brain Magnetic resonance image (MRI) scan detected a mass lesion in suprasellar area with T1 hypointensity and T2 hyperintensity and homogeneous enhancement. Recently, her parents complained with respected to her daytime somnolence and increase of sleep. Limb seizures appeared occasionally without conscious disturbance.
Physical examination was remarkable for her obesity and very short neck, with obvious apnea when sleeping. Coarse breath sounds were found on both sides of chest. Reexamined MRI showed the mass was enlargered (Figure 1). Chest computer tomography (CT) detected increased bronchovascular shadows and pulmonary congestion on bilateral pulmonary fields (Figure 2A). Results of laboratory test prompted central hypothyroidism, but also identified cortisol deficiency, coexisting with hyperosmolar status and hyperlipidemia (Table 2). No adjuvant hormone supplement was administered.

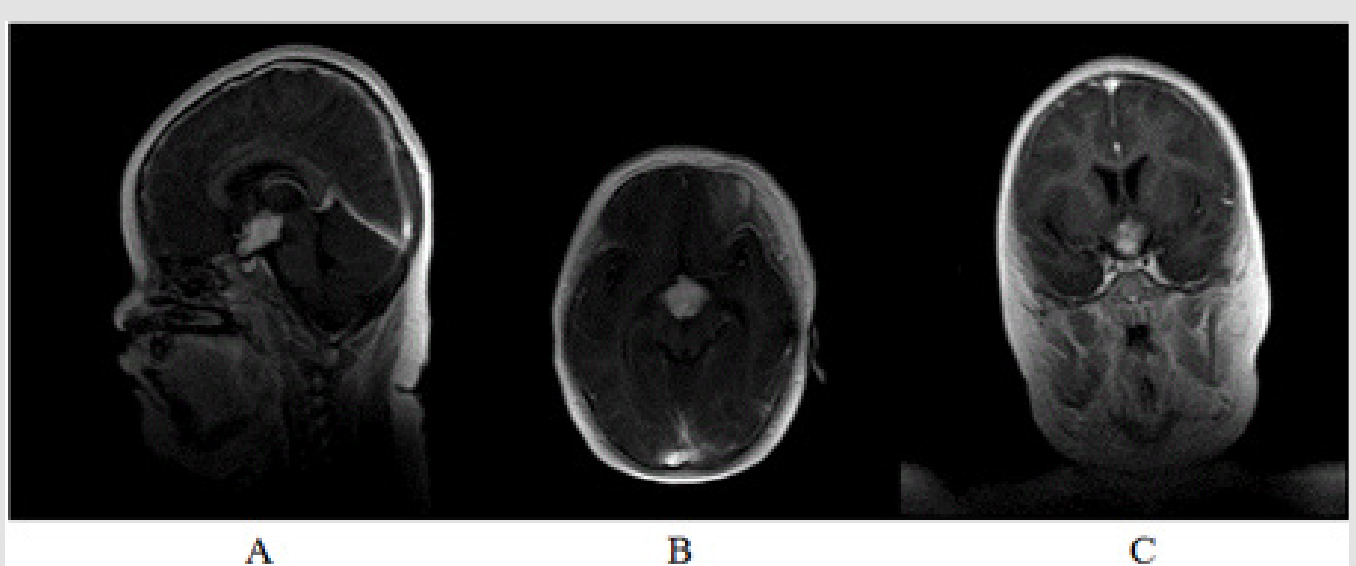

Figure 1: Preoperative brain MRI of the suprasellar lesion. T1 sagittal, T1 axial and T1 coronal sections showed a well-defined

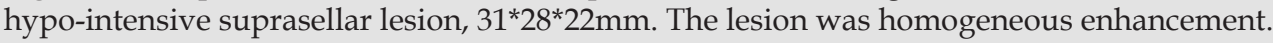

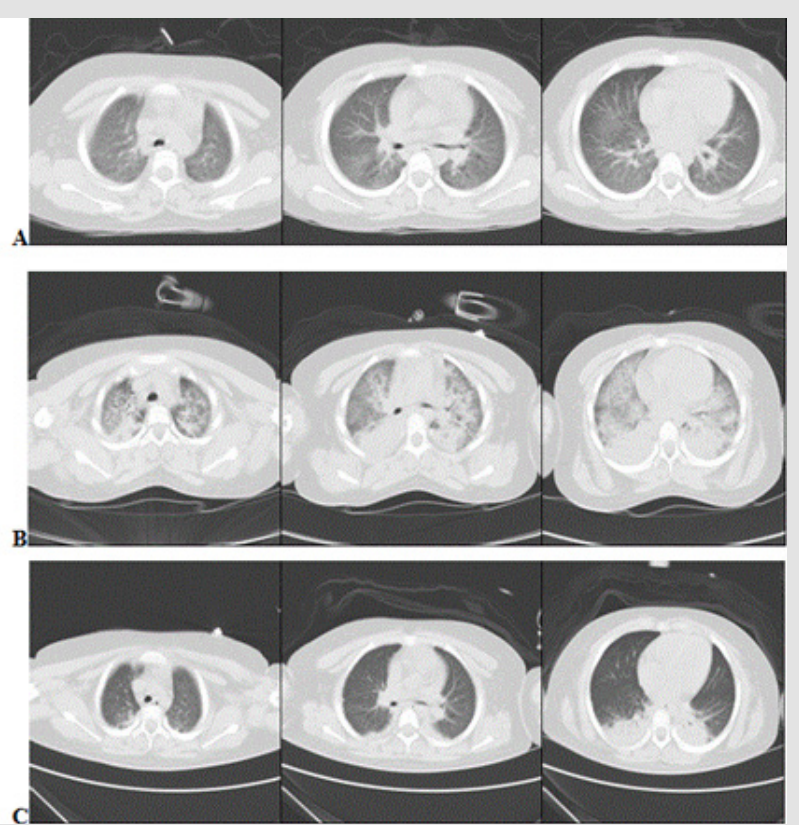

Figure 2: Preoperative axial cross-section images

A. Showed signs of pulmonary congestion with dilated pulmonary veins and bronchial cuffing, as well as thickened septal lines.

B. Intraoperative lung window revealed sever bilateral pulmonary edema with ground-glass opacity, concomitance with pulmonary consolidation and pulmonary effusion in bilateral lower lobes

C. Postoperative lung CT on admission ICU $48 \mathrm{~h}$ demonstrated most lung field clear except consolidation of bilateral lower lobes. 
Table 1: The demographic of two cases.

\begin{tabular}{|c|c|c|}
\hline & Case 1 & Case 2 \\
\hline Age & $5 Y 3 \mathrm{M}$ & Male \\
\hline Gender & Female & 35 \\
\hline Body weight $(\mathrm{Kg})$ & 32 & 113 \\
\hline Length $(\mathrm{cm})$ & 95 & 27.41 \\
\hline BMI $\left(\mathrm{Kg} / \mathrm{m}^{2}\right)$ & 35.46 & \\
\hline
\end{tabular}

BMI: Body Mass Index.

Table 2: The laboratory test parameter of two cases.

\begin{tabular}{|c|c|c|}
\hline & Case 1 & Case 2 \\
\hline ACTH $(<46 \mathrm{pg} / \mathrm{ml})$ & $<5$ & $<1.70$ \\
\hline Cortisol $(5 \sim 25 \mathrm{ug} / \mathrm{ml})$ & 1.41 & 5.013 \\
\hline TSH $(0.35 \sim 4.94 \mathrm{uI} / \mathrm{ml})$ & 2.696 & 4.67 \\
\hline Total T4 $(4.87 \sim 11.72 \mathrm{ug} / \mathrm{dl})$ & 3.27 & 0.67 \\
\hline Free T4 $(0.7 \sim 1.48 \mathrm{ng} / \mathrm{dl})$ & 0.56 & 3.57 \\
\hline TG $(0.1 \sim 1.7 \mathrm{mmol} / \mathrm{L})$ & 10.31 & 162 \\
\hline Na+ $(135 \sim 145 \mathrm{mmol} / \mathrm{L})$ & 154.8 & 128 \\
\hline Cl- $(95 \sim 110 \mathrm{mmol} / \mathrm{L})$ & 119.8 & 58.8 \\
\hline AST $(3 \sim 35 \mathrm{U} / \mathrm{L})$ & 39.9 & 266 \\
\hline$\alpha-\mathrm{HBDH}(72 \sim 182 \mathrm{U} / \mathrm{L})$ & 299 & 396 \\
\hline LDH $(120 \sim 250 \mathrm{U} / \mathrm{L})$ & 464 & \\
\hline ALP $(3 \sim 120 \mathrm{U} / \mathrm{L})$ & 499 & \\
\hline
\end{tabular}

ACTH: Adrenocorticotropic Hormone.

TSH: Thyroid Stimulating Hormone.

TG: Triglycride.

AST: Alanine Aminotransferase.

a-HBDH: Hydroxybutyrate Dehydrogenase.

LDH: Lactate Dehydrogenase.

ALP: Alkaline Phosphatase.

The patient was treated with levothyroxine and corticosteroid; homeostasis was monitored and adjusted daily. Four days after hospitalization, she underwent stereotactic biopsy with general anesthesia. However severe negative pressure pulmonary edema occurred during the process of induction (Figure 2B). Treatment of positive pressure ventilation was administrated immediately, accompanying with hormone supplement. After 48 hours intensive care, she recovered to preoperative status. Chest CT revealed bilateral lung fields were clear except consolidation on bilateral lower lobes (Figure 2C). Even the most of lung fields were clearer than preoperative CT images. However, her parents refused the second surgery for biopsy.

\section{Case 2}

A 5-year-old boy (Table 2) complained polydipsia and polyuria aboutoneyear, withoutrelevant medical history. Brian MRIidentified a suprasellar mass with $\mathrm{T} 1$ isointensity and T2 hyperintensity,

meanwhile it was heterogeneous enhancement. His body weight increased more than $15 \mathrm{~kg}$ in transient period, and somnolence with snoring was gradually obvious in recent couple of months. Physical examination demonstrated obesity and somnolence without other obvious symptoms. Reviewing brain MRI demonstrated the lesion was larger than the previous (Figure 3). Chest CT showed bilateral pleural opacity and increased bronchovascular shadows (Figure 4). Laboratory tests identified hypothyroidism and hypocortisolemia, as well as hyperosmolar status and hyperlipidemia (Table 2). After admission, he subsequently commenced levothyroxine and hydrocortisone supplement therapy, and homeostasis was maintained. Because of the lesson from the first case, he underwent stereotactic biopsy with local anesthesia. The operation was successful and pathological diagnosis based on microscope and immunohistochemical findings was Erdheim-Chester disease (ECD) (Figure 5). 


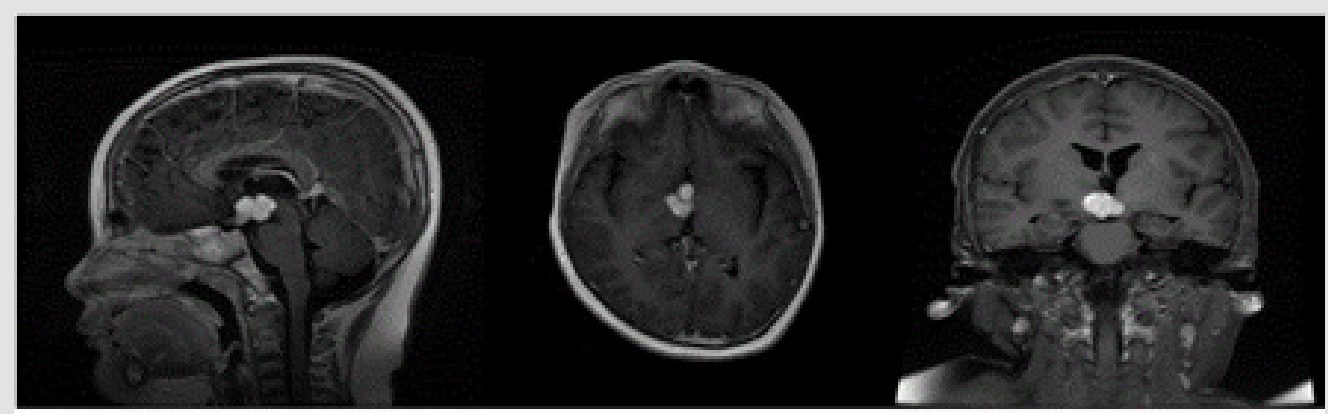

A

B

C

Figure 3: Preoperative magnetic resonance imaging of brain T1-weighted MRI

A. sagittal view,

B. axial view and

C. coronal view revealed mutilobulated complex mass in the suprasellar region mearsuring $23^{*} 17^{*} 15 \mathrm{~mm}$. The lesion was isointensive and heterogeneous enhancement.

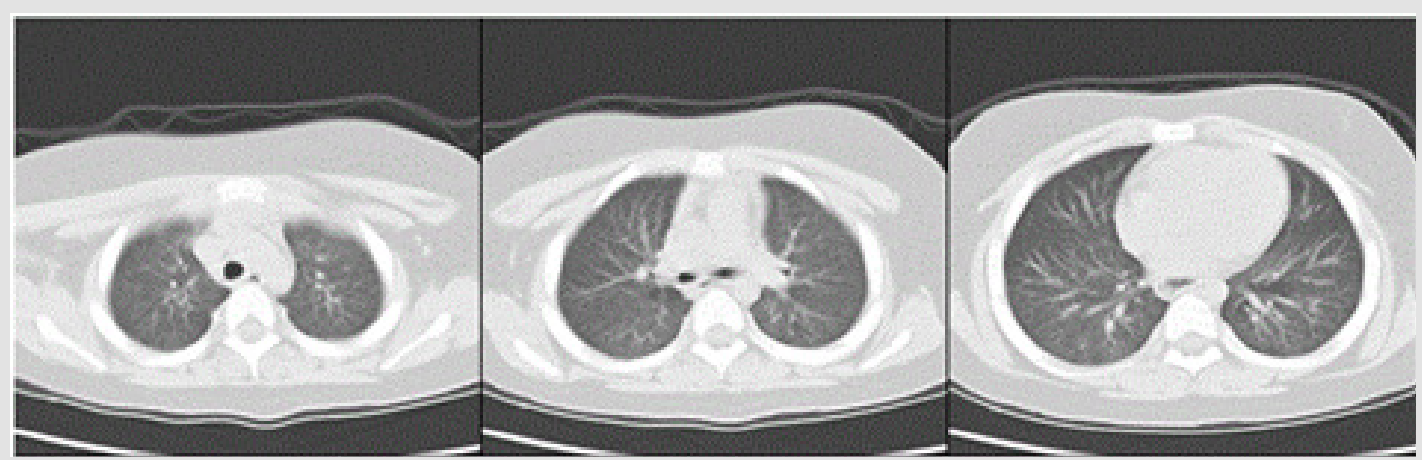

Figure 4: Lung window of CT taken on admission revealed bilateral opacity and interlobular septal thicking and peribronchovascular interstitial thickening.
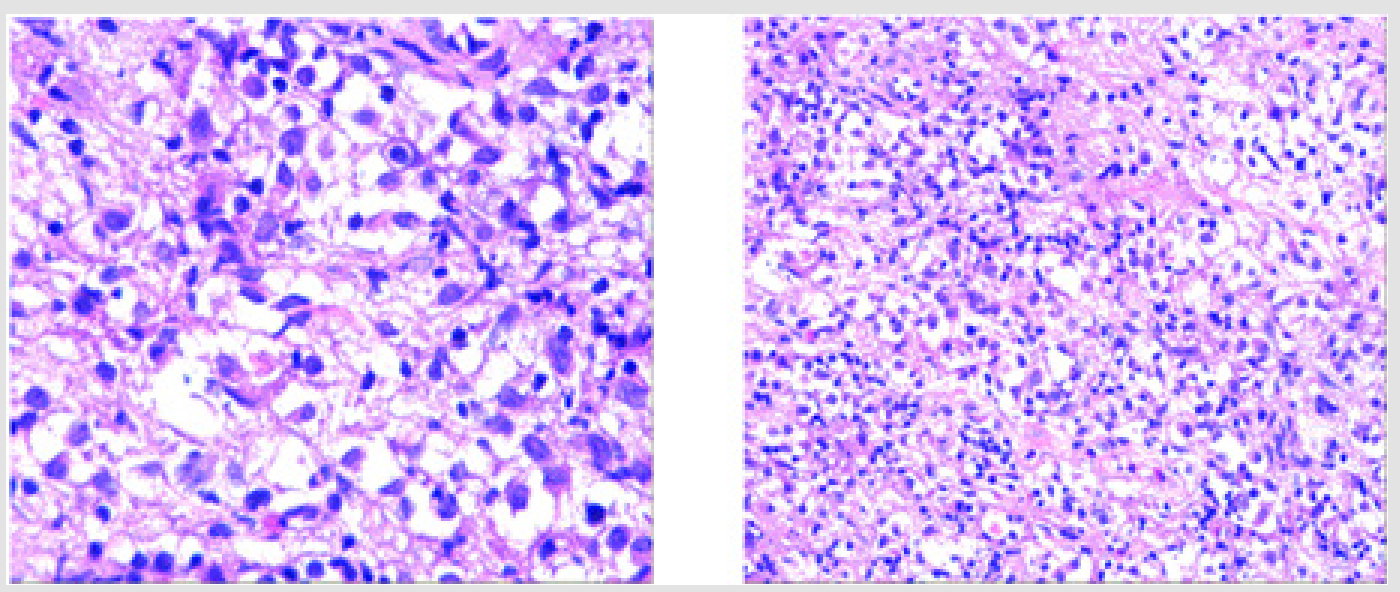

Figure 5: The results of immunohistochemistry of suprasellar lesion. GFAP (-), Olig-2 (-), S-100 (+), Vimentin (+), LCA (+), CD68 (+), CD3 (-), CD1a (-), CD163 (+), ATRX (+), IDH1R123H (+), Ki-67 (+5-15\%), P53 (+), CD117 (-), Oct3/4 (-), SALL4 (-), PLAP (-), H3K27M (-), MAC387 (-), BRAFV600E (+), BRAFV600 positive contrast $(+)$. The color photo is only available online.

\section{Discussion and Literature Review}

The most common clinical symptoms of sellar/suprasellar lesions appeared in the two cases, such as central hormones insufficiency, obesity, and sleep disorder. Besides that, they possessed obvious preoperative pulmonary congestion. Negligence of it made more severe pulmonary edema and consolidation in case 1 , thus more attention had to be paid on the second case with appropriate anesthesia strategy. Fellow-up confirmed the second case received promptly treatment due to the successful stereotactic biopsy. What etiologies did cause the preoperative pulmonary congestion? Pediatric sellar/suprasellar tumor share many clinical similarities 
due to their anatomic location adjacent to critical brain structures [7]. It is well knows, lesions penetrating in sellar/superasellar area frequently appear clinical manifestation of anterior pituitary gland insufficiency caused by compression of the pituitary stalk, such as diabetes insipidus, obesity, circadian rhythm disorders, and so on [8]. Both of them were in state of hypothyroidism. For lung development, lung defence and surfactant synthesis, thyroid hormone is very important. Alteration of thyroid hormone level might affect lung function and central respiratory drive [9]. In 2015, Al-Sofiani reported a female case of non-cardiogenic pulmonary edema with history of hypothyroidism. The patient was not only with a normal ejection fraction, but also with sleep apnea. So her statue was similar to the above two cases. Different from cardiogenic pulmonary edema, non-cardiac pulmonary is based on change of alveolar capillary membrane permeability. Hypothyroidism was believed to induce non-cardiogenic pulmonary edema indirectly $[10,11]$. Because hypothyroidism might increase pulmonary capillary permeability and induce plasma proteins leakage [12], severe hypothyroidism might increase pleural effusion, which was associated with restrictive pulmonary function and respiratory failure [13].

Along with hypothyriodism, hypocortisolism also occurred in the two cases. Patients with hypocortisolism might be suspected to be more vulnerable to lung leaking syndrome [14], because cortisol may decrease capillary permeability and ameliorate lung endothelial barrier dysfunction. Both mechanisms are strongly associated with mortality of septic shock $[15,16]$. As to other diseases based on pulmonary endothelial injury and/or capillary permeability increment, for instance ARDS, especially nonresolving ARDS, glucocorticosteroids might be an effective rescue option [17]. Although some authors reported not less than 20\% patients with ARDS were administrated systemic steroids [18], its role in early ARDS remains controversial [19]. We reported the two cases with onset of hormone supplement treatment as soon as possible. In case 1 , corticosteroid did promote resolution of respiratory failure, confirmed by chest CT fellow-up.

There are other traits of sellar/supresellar lesion in the two cases, such as obesity, sleep disorder. The body mass index (BMI) of the first case was $35 \mathrm{~kg} / \mathrm{m}^{2}$, meanwhile, body weight of the second case increased $15 \mathrm{~kg}$ in short time, so as to his BMI was $27 \mathrm{~kg} / \mathrm{m}^{2}$. Sleep disorder was another remarkable sign, case 1 showed severe obstructive sleep apnea (OSA), and parents of case 2 complained his somnolence and snoring. Whatever obesity and sleep disorder, such signs are results of hypothalamic neuroendocrine disturbance, which is commonly related with space-occupyingeffect and/or penetration of sellar/suprasellar lesion $[6,8,20]$. Vice versa, obesity with OSA not only disturbs concentration and rhythm of hormones, but also impairs peripheral sensitivity to hormones [21]. This is a vicious circle. So we suspected there were some associations between obesity with sleep disturbance and pulmonary congestion, even pulmonary edema. At least it could indirectly accelerate pulmonary pathological alteration by induction of hormone disturbance. Obesity is a status of increase of systemic and pulmonary circulations. In obese patient, elevation of pulmonary capillary blood volume causes subclinical interstitial edema due to abnormal alveolar membrane diffusion. In 2016, Oppenheimer and colleague observed a group of obese patients, who were with variable degrees of pulmonary vascular congestion, but no clinical cardiopulmonary dysfunction manifestation. Their results demonstrated alveolar membrane structure and pulmonary vascular permeability might change in these obese patients. Because airway compression and inflammation caused by obesity per se, these patients were vulnerable to pulmonary edema [22].

The characteristics of sleep disorder of both cases were OSA and snoring respectively. These signs are connected with upper airway obstruction. Because generation of negative intrathoracic press is more remarkable during obstructive episodes, pulmonary edema has been observed as a presenting symptom of OSA [23]. Breathing work is increased because of futile efforts against to closed upper airway. Excessive inspiration concomitant with repeated airway collapse produces exaggerated negative intrathoracic pressure fluctuation, which might raise left ventricular afterload provoking pulmonary congestion [24]. Additional reason we presented the two cases owing to the second case with ECD, confirmed by pathological diagnosis. ECD is a proliferative disorder of non-Langerhans histiocytes with extremely low rate in children. About 550 cases have been reported in the literature to date, and pediatric ECD is ultra-rare [25]. There were only no more than 7 cases of pediatric ECD reported in PubMed and PMC literature till 2014 [26,27]. Recently another 7 cases of pediatric ECD were reported again from 2014. In these cases, intracranial ECD were more extremely rare. The second case in this report was just 5-year-old boy and the forth youngest ECD in PubMed and PMC literature until now, additional young cases included a 17-month-old, a 2-year-old and a 3-year-old respectively [28-30]. However we focused on his clinical problem related to anesthesia, but not the pathophysiological of ECD.

\section{Limitation}

In the two cases, diagnosis of hormones insufficiency, the location of lesion, and pulmonary congestion was very definite due to radiological evidences and laboratory parameters. However the state of sleep disorder was assessed without objective index, besides of indirectly cues and some risks, such as obesity, apnea, excessive sleep and snoring. The 'golden standard' of OSA is apneahypopnea index of polysomngraphy [31], because our institution is a specialized neurosurgical hospital, overnight polysomnography test cannot be carried there. In addition, the extended time between diagnosis of brain lesion and occurrence of sleep disorder made parents of these two cases neglect connection between abnormal sleep and brain tumor. So the two cases had never received sleep referral. In fact, patients of sellar/suprasellar tumor with obesity are more likely at greater risk of sleep disorder breathing, however these symptoms related to sleep disturbance could not be identified early until diagnosis of tumor on sellar/suprasellar region [32]. 


\section{Conclusion}

Because of space-occupying effect and/or penetrating pituitary, sellar/suprasellar lesions often produce central hormonal deficiencies. Hormone disturbances put patients of sellar/suprasellar mass in high risk of obesity, which increases the possibility of developing sleep-disorder breathing or OSA. Compared to the mean of age and gender, the risk of OSA might raise $12 \%$ follow every increase in BMI of $1 \mathrm{~kg} / \mathrm{m}^{2}$ [33]. These disorders increase difficulties of general anesthesia, especially airway management. Besides, they work together to induce and accelerate pulmonary pathological changes, thus pulmonary congestion occurs. Coexistence sellar/suprasellar lesion with pulmonary congestion is very rare. Awareness is need of new pathological entities in sellar/suprasellar lesions, therefore more attention should be pay on preoperative evaluation and makeup of anesthesia plan and otherwise there might be disaster.

\section{Informed consent}

Informed parental consent was obtained from the individual included in the study.

\section{Acknowledgment}

Not available.

\section{Ethical Statement}

We informed the ethics committee of Sanbo Brain Hospital, Capital Medical University, and got its approval (Permit No.SBNKYJ-2019-010-01).

\section{References}

1. Abushamat LA, Kerr JM, Lopes MBS, Kleinschmidt-De Masters BK (2019) Very Unusual Sellar/Suprasellar Region Masses: A Review. J Neuropathol Exp Neurol pii: nlz044.

2. Mangussi-Gomes J, Gentil AF, Filippi RZ, Momesso RA, Handfas BW, et al. (2019) Sellar and suprasellar arachnoid cyst. Einstein (Sao Paulo) 17(1) eAI4269.

3. Norris GA, Garcia J, Hankinson TC, Handler M, Foreman N, et al. (2019) Diagnostic accuracy of neuroimaging in pediatric optic chiasm/sellar/ suprasellar tumors. Pediatr Blood Cancer 66(6): e27680.

4. Hershey B (1993) Suprasellar masses: diagnosis and differential diagnosis. Semin Ultrasound CT MR 14(3): 215-231.

5. Kadashev BA, Konovalov AN, Astaf'eva LI, Kalinin PL, Kutin MA, et al (2018) Preoperative and postoperative endocrine disorders associated with pituitary stalk injuries caused by suprasellar growing tumors. Zh Vopr Neirokhir Im N N Burdenko 82(1): 13-21.

6. Van Iersel L, Brokke KE, Adan RAH, Bulthuis LCM, van den Akker ELT, et al. (2019) Pathophysiology and Individualized Treatment of Hypothalamic Obesity Following Craniopharyngioma and Other Suprasellar Tumors: A Systematic Review. Endocr Rev 40(1): 193-235.

7. Mc Crea HJ, George E, Settler A, Schwartz TH, Greenfield JP (2016) Pediatric Suprasellar Tumors. J Child Neurol 31(12): 1367-1376.

8. Andrysiak-Mamos E, Sagan K, Sagan L, Sowińska-Przepiera E, Syrenicz A (2018) Cystic lesions of the sellar-suprasellar region-diagnosis and treatment. Endokrynol Pol 69(2): 212-228.

9. Milla CE, Zirbes J (2012) Pulmonary complications of endocrine and metabolic disorders. Paediatr Respir Rev 13(1): 23-28.
10. Antonelli D, Barzilay E, Lev A, Dar H (1985) Non-cardiac pulmonary edema: an enigma today. Minerva Med 76(39): 1819-1822.

11. Al-Sofiani M, Nikolla D, Metta VV (2015) Hypothyroidism and noncardiogenic pulmonary edema: are we missing something here? Endocrinol Diabetes Metab Case Rep 2015: 150014

12.Vinaya S Karkhanis, Jyotsna M Joshi (2012) Pleural effusion: diagnosis, treatment, and management. Open Access Emerg Med 4: 31-52.

13. Brüssel T, Matthay MA, Chernow B (1989) Pulmonary manifestations of endocrine and metabolic disorders. Clin Chest Med 10(4): 645-653.

14.Xiong J, Sun YX (2019) Negative pressure pulmonary edema: a case report. BMC Anesthesiol 19(1): 63

15. Shulman DI, Palmert MR, Kemp SF; Lawson Wilkins Drug and Therapeutics Committee (2007) Adrenal insufficiency: still a cause of morbidity and death in childhood. Pediatrics 119(2): e484-494.

16. Barabutis N, Khangoora V, Marik PE, Catravas JD (2017) Hydrocortisone and Ascorbic Acid Synergistically Preventand Repair LipopolysaccharideInduced Pulmonary Endothelial Barrier Dysfunction. Chest 152(5): 954 962

17. Diana P, Money DT, Gelvin MG, Lunardi N (2017) Effective and Safe Use of Glucocorticosteroids for Rescue of Late ARDS. Case Rep Crit Care 2017: 6740532

18. Bellani G, Laffey JG, Pham T, Fan E, Brochard L, et al. LUNG SAFE Investigators; ESICM Trials Group (2016) Epidemiology, Patterns of Care, and Mortality for Patients With Acute Respiratory Distress Syndrome in Intensive Care Units in 50 Countries. JAMA 315(8): 788-800.

19. Matthay MA, Zemans RL, Zimmerman GA, Arabi YM, Beitler JR, et al. (2019) Acute respiratory distress syndrome. Nat Rev Dis Primers 5(1): 18.

20. Balcázar-Hernández L, Vargas-Ortega G, Valverde-García Y, MendozaZubieta V, González-Virla B (2017) Anorexia-cachexia syndrome-like hypothalamic neuroendocrine dysfunction in a patient with a papillary craniopharyngioma. Endocrinol Diabetes Metab Case Rep pii: 17-0018.

21. Lanfranco F, Motta G, Minetto MA, Baldi M, Balbo M, et al. (2010) Neuroendocrine alterations in obese patients with sleep apnea syndrome. Int J Endocrinol 2010: 474518.

22. Oppenheimer BW, Berger KI, Ali S, Segal LN, Donnino R, et al. (2016) Pulmonary Vascular Congestion: A Mechanism for Distal Lung Unit Dysfunction in Obesity. PLoS One 11(4): e0152769.

23. Medford ARL (2012) Negative pressure pulmonary edema: consider undiagnosed obstructive sleep apnea too. Chest 141(5): 1365

24. Naughton MT, Bradley TD (1998) Sleep apnea in congestive heart failure. Clin Chest Med 19(1): 99-113.

25. Mohammad Adawi, Bishara Bisharat, Abdalla Bowirrat (2016) ErdheimChester disease (ECD): Case report, clinical and basic investigations, and review of literature. Medicine (Baltimore) 95(42): e5167.

26. Tran TA, Pariente D, Guitton C, Delwail A, Barat-Houari M, et al. (2014) Treatment of Erdheim-Chester disease with canakinumab. Rheumatology (Oxford) 53(12): 2312-2314.

27. Mazor RD, Manevich-Mazor M, Shoenfeld Y (2013) Erdheim-Chester Disease: a comprehensive review of the literature. Orphanet J Rare Dis 8: 137.

28. S Eyssette-Guerreau, C Job-Deslandre, M Taghian, J Donadieu, P Thierry, et al. (2008) Erdheim-Chester disease in children: clinical, radiologic, treatment characteristics of three cases. Pediatr Rheumatol Online J 6(Suppl 1): P129.

29. Váradi Z, Bánusz R, Csomor J, Kállay K, Varga E, et al. (2017) Effective BRAF inhibitor vemurafenib therapy in a 2-year-old patient with sequentially diagnosed Langerhans cell histiocytosis and Erdheim-Chester disease. Onco Targets Ther 10: 521-526. 
30. Kim S, Lee M, Shin HJ, Lee J, Suh YL (2016) Coexistence of intracranial Langerhans cell histiocytosis and Erdheim-Chester disease in a pediatric patient: a case report. Childs Nerv Syst 32(5): 893-896.

31. Jordan AS, Mc Sharry DG, Malhotra A (2014) Adult obstructive sleep apnoea. Lancet 383(9918): 736-747.

32. Mandrell BN, Wise M, Schoumacher RA, Pritchard M, West N, et al. (2012) Excessive daytime sleepiness and sleep-disordered breathing

ISSN: 2574-1241

DOI: 10.26717/BJSTR.2020.27.004454

Yongxing Sun. Biomed J Sci \& Tech Res

(C) This work is licensed under Creative

Submission Link: https://biomedres.us/submit-manuscript.php disturbance in survivors of childhood central nervous system tumor Pediatr Blood Cancer 58(5): 746-751

33. Redline S, Tishler PV, Schluchter M (1999) Risk factors for sleepdisordered breathing in children: associations with obesity, race, and respiratory problem. Am J Respir Crit Care Med 159: 1527-1532.

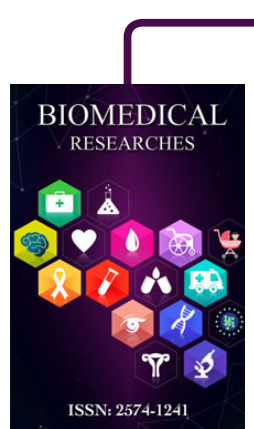

Assets of Publishing with us

- Global archiving of articles

- Immediate, unrestricted online access

- Rigorous Peer Review Process

- Authors Retain Copyrights

- Unique DOI for all articles

https://biomedres.us/ 